Confiabilidade de prensas excêntricas horizontais paralelas de uma linha de fabricação de embalagens metálicas para bebidas

\title{
Reliability of partial horizontal eccentric presses of a metal packaging manufacturing line for
} beverages

Ronaldo Rodrigues da Silva ${ }^{1}$ - Instituto Luterano de Ensino Superior

Tamires Sousa Araújo ${ }^{2}$, Universidade Federal de Mato Grosso do Sul

\section{RESUMO}

Com o passar do tempo, a manutenção deixou de ser uma atividade corriqueira nas organizações e se tornou fator primordial para a confiabilidade e disponibilidade dos processos produtivos. Com o objetivo de demonstrar a eficiência dos cálculos de Confiabilidade e, assim, propor a Metodologia da Confiabilidade como ferramenta de melhoria em um processo de manutenção de uma linha de produção automatizada foi realizado um relato técnico da aplicação de indicadores de manutenção num ambiente de manufatura em uma multinacional fabricante de latas de alumínio para bebidas. Os cálculos de Confiabilidade foram aplicados em uma linha com nove Prensas Excêntricas Horizontais em paralelo, do setor de estamparia. Para a pesquisa, foram coletados dados históricos de tempo até o reparo e tempo entre falhas do equipamento em estudo. Com o auxílio do software Excel 2013® foi calculado Tempo Médio para Reparo, o Tempo Médio Entre Falha, a Disponibilidade e, por fim, a Confiabilidade individual e do sistema. Com base nos resultados obtidos, identificou-se que o equipamento estudado está em uma fase que apresenta pouco desgaste e que não poderia relatar o número de falhas em um período curto, porém os cálculos evidenciam a relevância do seguimento de manutenção planejada. Assim, o presente estudo indica a manutenção preventiva como uma nova estratégia para prevenir as falhas.

Palavras-chave: Manutenção. Disponibilidade. Confiabilidade.

\section{ABSTRACT}

Over time, maintenance has ceased to be a routine activity in organizations, and has become a primary factor for the reliability and availability of production processes. With the objective of demonstrating the efficiency of Reliability calculations and, thus, to propose the Reliability Methodology as a tool for improvement in a process of maintenance of an automated production line, a technical report on the application of maintenance indicators in a manufacturing environment was carried out in a multinational manufacturer of aluminum cans for beverages. The Reliability calculations were applied in a line with nine Horizontal Eccentric Presses in parallel, Press Shop. For the research, historical data from time to repair (TTR) and time between failures $(T B F)$ of the equipment under study were collected. With the help of the Excel 2013® software, Average Time to Repair (MTTR), Mean Time Between Failure $(M T B F)$, Availability and, finally, individual and system Reliability were calculated. Based on the results obtained, it was identified that the equipment studied is in a phase that presents little wear and could not report the number of failures in a short period, but the calculations show the relevance of the planned maintenance follow-up. Thus, the present study indicates a new strategy, preventive maintenance, to prevent failures.

Keywords: Maintenance. Availability. Reliability.

1.Avenida Beira Rio, 1001 - St. Nova Aurora, Itumbiara - GO, CEP: 75522-330, ronaldors832010@gmail.com; 2. tamiresousa124@hotmail.com

SILVA, R.R.; ARAÚJO, T.S. Confiabilidade de prensas excêntricas horizontais paralelas de uma linha de fabricação de embalagens metálicas para bebidas. GEPROS. Gestão da Produção, Operações e Sistemas, v. 15, n. 2, p. 253 - 287, 2020.

DOI: $10.15675 /$ gepros.v15i2.2516 
Confiabilidade de prensas excêntricas horizontais paralelas de uma linha de fabricação de embalagens metálicas para bebidas

\section{INTRODUÇÃO}

Por muito tempo a manutenção foi vista como um gasto desnecessário ou considerada um custo alto para as empresas e, por isso, não se investia muito em manutenção. Esse fato mudou de cenário, já que um processo competitivo necessita de rapidez na produção, o que exige cada vez mais de máquinas e equipamentos. Sendo que para uma maior disponibilidade desses sistemas produtivos é necessário um bom plano de manutenção, evidenciando a importância da manutenção para a confiabilidade nos processos produtivos (CERVEIRA; SELLITTO, 2015).

Para Oliveira, Paiva e Paiva (2019, p. 72), “a Gestão da Manutenção deve incorporar a Engenharia como o agente direcionador dos processos de rotina e melhorias. De forma prática, a empresa deve trabalhar para evitar as falhas ou, no mínimo, prevê-las". Uma proposta viável para a gestão da manutenção seria um planejamento com princípios baseados na teoria da confiabilidade. A fase de projeto e implantação é extremamente importante para a confiabilidade e disponibilidade do maquinário instalado, já que a análise de partes mais frágeis ou aquelas que vão exercer maiores esforços são identificadas ainda no processo de implantação, diminuindo a complexidade de possíveis modificações após a instalação das máquinas (SELLITO, 2007).

Sendo assim, as paradas não programadas das máquinas em estudo (Prensas Excêntricas Horizontais) causam, além de atrasos na produção, mais dois problemas nos processos subsequentes. O primeiro problema seria a diminuição da velocidade de operação das máquinas e o segundo seria as máquinas entrarem em espera (standby). Nos dois casos são necessários novos ajustes em todos os parâmetros de operação das máquinas, o que gasta tempo que poderia ser usado para produzir. Com base nessas problemáticas, tem-se a seguinte pergunta: De que forma os cálculos de confiabilidade e disponibilidade contribuem para o planejamento da manutenção das máquinas em estudo?

Ao buscar responder esse problema de pesquisa, o presente trabalho configura-se como um relato técnico da aplicação de indicadores de manutenção num ambiente de manufatura com o objetivo de propor a Metodologia da Confiabilidade como ferramenta de melhoria em um processo de manutenção de uma linha de produção automatizada em uma Multinacional. 
Confiabilidade de prensas excêntricas horizontais paralelas de uma linha de fabricação de embalagens metálicas para bebidas

O estudo mostra-se relevante visto que as paradas não planejadas das máquinas, ocasionadas por uma metodologia ineficiente de manutenção, causam indisponibilidade dos equipamentos do processo. Com isso ocorrem atrasos na produção e aumento dos custos operacionais, o que diminui a qualidade do produto final e afeta o relacionamento com o cliente, e, ainda, pode gerar danos materiais e humanos, contribuindo para uma imagem negativa da organização (NUNES, 2001). Outra importância é a competitividade, Oliveira e Silva (2013, p. 54) apresentam que "a redução de custos de produção é fator primordial para a viabilização do negócio, e a manutenção adquire valor estratégico".

Portanto, tal estudo se justifica pela importância de mostrar para os gestores da organização em estudo que a prática de manutenção é relevante. Além disso, é importante mostrar a necessidade de escolha de modelos para um ciclo de manutenção, cujo planejamento se respalda nas coletas e análises de dados, e que tem como base as Metodologias de Confiabilidade. Tais fatos trazem para a empresa vantagens como: a integração entre operação e manutenção, redução de custos com mão de obra e materiais utilizados nas intervenções, e capacidade de oferecer produtos e serviços diferenciados (SELLITTO, 2007).

Outra justificativa é evidenciar de forma prática para engenheiros a importância da gestão da manutenção e sua confiabilidade para um processo produtivo (MARIN et al., 2016). Para Oliveira, Paiva e Paiva (2019, p. 72), “a Gestão da Manutenção deve incorporar a Engenharia como o agente direcionador dos processos de rotina e melhorias". A justificativa científica do presente estudo é a falta de estudos científicos no Brasil que evidenciam na pratica a relevância da manutenção em industrias, podendo assim, apresentar a importância das manutenções preventivas neste setor. Costa (2013) aponta que o tema manutenção eficiente é pouco discutido na academia, com poucas informações são discutidas na graduação, o que salienta a necessidade de trabalhos que abordem a temática.

Desta forma, conhecer o real estado de operação de máquina e equipamento torna a gestão da manutenção mais eficaz e assertiva, pois direciona todos os recursos e atenção ao que é realmente causador dos defeitos e falhas na produção. 
Confiabilidade de prensas excêntricas horizontais paralelas de uma linha de fabricação de embalagens metálicas para bebidas

\section{REFERENCIAL TEÓRICO}

\subsection{Manutenção industrial}

A norma 5462 da Associação Brasileira de Normas Técnicas (ABNT, 1994) define manutenção como ações técnicas e de gestão, com o objetivo de manter ou recolocar algo em plenas condições para exercer sua função. 'Manter' significa realizar intervenções que permitam conservar o potencial da máquina ou conjunto de equipamentos, para garantir a assiduidade e as condições necessárias para exercer sua função (SOUZA, 2008). Para Oliveira e Silva (2013, p. 54) a manutenção em "uma definição mais atual poderia ser: um conjunto de ações de gestão, técnicas e econômicas, aplicadas ao bem, com o objetivo de mantê-lo, aumentando seu ciclo de vida".

Costa (2013) afirma que o termo manutenção tem sua raiz na verbalização militar, cujo significado era conservar nas unidades de batalha o efetivo e os equipamentos em um nível constante de disponibilidade para as operações. Sendo que o ato de conservar tem como significado a própria manutenção industrial, que possui o objetivo de deixar sempre disponível de forma efetiva os equipamentos que fazem parte de um processo produtivo, sem agredir o meio ambiente e com baixos custos.

A manutenção está diretamente ligada aos sistemas produtivos e à disponibilidade dos equipamentos, sendo ela um dos principais apontadores de confiabilidade nos programas de manutenção. As ações de manutenção se classificam em corretivas e preventivas. A manutenção corretiva é um conjunto de ações realizadas quando um equipamento ou sistema para de funcionar sem aviso prévio e tem como objetivo torna-los operantes novamente. Já a manutenção preventiva, utiliza-se de cuidados periódicos com o objetivo de manter o bom funcionamento dos equipamentos, evitando paradas imprevistas (FOGLIATTO; RIBEIRO, 2011).

Nogueira, Guimarães e Silva (2012) e Costa (2013) alegam que o tipo de manutenção depende de como é feita a intervenção necessária para garantir a disponibilidade do equipamento ou sistema produtivo. Apesar de serem citadas várias formas de manutenção, existe um consenso em torno de cinco práticas de manutenção: manutenção corretiva planejada e não planejada, manutenção preventiva, manutenção preditiva e manutenção produtiva total (TPM). 
Confiabilidade de prensas excêntricas horizontais paralelas de uma

linha de fabricação de embalagens metálicas para bebidas

Costa (2013) destaca que a manutenção corretiva é considerada como a prática de manutenção mais arcaica, pois só é aplicada após a quebra do equipamento, não havendo nenhum cuidado para se evitar a falha. Trata-se de uma manutenção que corrige imediatamente o que estiver de errado com o equipamento, sem qualquer planejamento prévio. Apesar de ser um tipo de manutenção entregue à eventualidade, ele se divide em duas categorias: manutenção corretiva planejada e não planejada.

A manutenção corretiva planejada é uma prática na qual se chega a um consenso gerencial em monitorar o equipamento por meio de técnicas preditivas ou em deixar o equipamento atuar até sua falha. A eficiência desse tipo de manutenção está ligada à precisão dos dados fornecidos pelo acompanhamento preditivo ou pela qualidade da decisão gerencial, possibilitando um planejamento para tentar diminuir os custos e as perdas de produção durante a correção da falha, isso pelo fato de que tal falha já é esperada (NOGUEIRA; GUIMARÃES; SILVA, 2012).

A manutenção corretiva não planejada é uma prática ocasional que só é realizada após a falha ou a perda de eficiência do equipamento e não possui planejamento prévio e nem qualquer tipo de monitoramento. Pelo fato do efetivo de manutenção não ser esperado, faz-se com que o reparo do erro seja mais demorado e com custos mais elevados, o que pode evoluir para danos maiores ou, até mesmo, transferir falhas para outros componentes do equipamento, diminuindo a confiabilidade e a disponibilidade dos processos (COSTA, 2013).

De acordo com Souza (2008), a aplicação de manutenções corretivas exige que os efetivos de manutenção estejam sempre atentos e prontos para reagir a qualquer falha que ocorrer para poder corrigi-la imediatamente, o que gera um custo elevado de mão de obra de manutenção. Sendo assim, os consertos realizados no modo corretivo tornam os custos totais de manutenção bem maiores do que quando se aplica uma metodologia preventiva.

Sobre a manutenção preventiva, Souza e Lima (2003) relatam que ela consiste em ações periódicas destinadas a manter, reestabelecer ou acompanhar algum equipamento, com o objetivo de deixá-lo sempre em condições ideais de funcionamento. Essas ações são tecnicamente viáveis quando se possui um ponto conhecido da crescente taxa relativa de falha, quando a maior parte dos componentes resiste até o período necessário e quando se repara o componente, deixando-o com suas funcionalidades iniciais.

Por se tratar de uma metodologia preventiva, baseia-se em serviços planejados periodicamente. Para que esses períodos de tempo possuam a qualidade esperada e o tempo GEPROS. Gestão da Produção, Operações e Sistemas, v. 15, nº 2, p. 253 - 287, 2020. 
Confiabilidade de prensas excêntricas horizontais paralelas de uma linha de fabricação de embalagens metálicas para bebidas

certo, é necessário haver uma excelente estimativa de tempo entre cada intervenção, pois, em caso de incertezas, poderá ser estimado um período de tempo menor do que o necessário e, com isso, haverá paradas desnecessárias para a manutenção (OTANI; MACHADO, 2008). Correia e Dias (2016, p. 268) discorrem que "apesar de a manutenção preventiva possibilitar antecipação da correção da avaria, antes que a falha ocorra, ela também gera indisponibilidade no processo, pois para cada evento de manutenção existe a necessidade de parada do processo", o que torna o processo completo.

Quando é conhecido o grau de deterioração do equipamento, a manutenção preventiva passa a ser sistêmica. Esse grau de deterioração ou grau de degradação significa que o efetivo de manutenção está ciente do nível de desgaste do equipamento, que varia conforme sua utilização. Tal ação de desgaste acontece de modo mais rápido se o equipamento for usado de forma imprópria (NUNES, 2001).

Pode-se entender que quando o grau de deterioração não é conhecido, a manutenção antes baseada na condição e no período, passa a ser de acompanhamento ou preditiva. Sendo que a manutenção preditiva acontece quando há uma monitoração das condições de funcionamento do equipamento a fim de utilizar ao máximo a vida útil de seus componentes.

Baran (2011) relata no seu estudo que a falha de equipamento sempre é antecedida por algum sintoma que um dos seus componentes emite e monitorando tais sintomas é possível predizer a real condição de funcionamento do equipamento e, assim, identificar a periodicidade das intervenções de manutenção. Marçal (2000) faz uma afirmação complementar ao confirmar que o acompanhamento dos sintomas emitidos pelos componentes dos equipamentos possibilita um planejamento futuro de manutenção baseado nas condições presentes dos componentes.

Marçal (2000) resume que a manutenção preditiva consiste em acompanhar a máquina, sem afetar seu funcionamento, por meio de aparelhos de medições para prognosticar eventuais variações ou mudanças de comportamento fora da rotina de seu funcionamento, a fim de possibilitar o planejamento da manutenção no tempo certo, aproveitando ao máximo a vida útil do equipamento. O Quadro 1 apresenta as formas de manutenção e exemplos: 
Confiabilidade de prensas excêntricas horizontais paralelas de uma linha de fabricação de embalagens metálicas para bebidas

Quadro 1 - Formas de Manutenção

\begin{tabular}{|c|c|c|c|}
\hline & Manutenção Corretiva & Manutenção Preventiva & $\begin{array}{c}\text { Manutenção } \\
\text { Preditiva }\end{array}$ \\
\hline $\begin{array}{c}\text { Estado de funcionamento } \\
\text { da máquina }\end{array}$ & Fora de serviço & Fora de serviço & Em serviço ou fora \\
\hline Motivo da intervenção & Falha & Inspeção programada & $\begin{array}{c}\text { Controle programado } \\
\text { ou continuo }\end{array}$ \\
\hline $\begin{array}{c}\text { Tarefas a serem } \\
\text { realizadas na máquina }\end{array}$ & Troca de componentes & $\begin{array}{c}\text { Desmontagem para } \\
\text { inspeção e troca de } \\
\text { componente }\end{array}$ & Mediçães \\
\hline Objetivo da intervenção & Retorno ao serviço & $\begin{array}{c}\text { Garantir o funcionamento } \\
\text { por um determinado } \\
\text { período }\end{array}$ & $\begin{array}{c}\text { Predizer e detectar } \\
\text { falhas }\end{array}$ \\
\hline
\end{tabular}

Fonte: Adaptado de Marçal (2011).

Guevara, Cardenas e Camperos (2015, p. 130) apresentam que "a maioria dessas ferramentas e metodologias buscam alcançar a melhor relação custo/risco/benefício nas ações realizadas para conservar e restaurar a função dos ativos”. Entre as técnicas de manutenção preditiva, destaca-se a termográfica, que permite realizar diagnóstico e análise de tendências a partir de resultados de ensaios e da análise dos fenômenos que possam vir a ocorrer durante a operação de um equipamento (MARQUES et al., 2013).

A termografia é fundamentada em conjuntos de critérios e de atos técnicos que têm em vista a durabilidade e a longevidade de equipamentos e suas instalações. Assim, ao ocorrer algum indício e/ou quando constatado alguma disposição a falhas prematuras em máquinas e equipamentos, são planejadas ações preventivas. Se ocorrer um defeito ou uma falha imprevista, são realizadas as chamadas ações corretivas de natureza de urgência, como mostra a Figura 1 (MARQUES et al., 2013). 
Confiabilidade de prensas excêntricas horizontais paralelas de uma linha de fabricação de embalagens metálicas para bebidas

Figura 1 - Esquema Simplificado dos Procedimentos de Manutenção

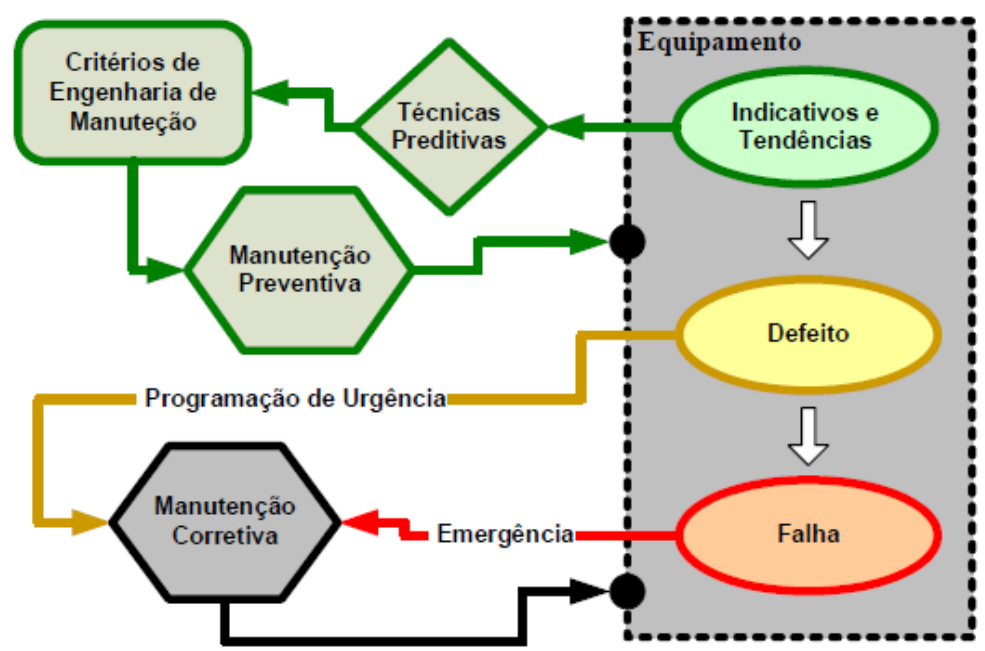

Fonte: Adaptado de Marques et al. (2013).

Para prever defeitos ou falhas em máquinas e equipamentos, utiliza-se as práticas preditivas de manutenção por meio de acompanhamento ou análise do real estado de operação das máquinas e equipamentos, ou ainda, baseia-se em informações com as quais se possam concluir deteriorações ou processos de degradação (MARQUES et al, 2013).

A termografia, também chamada de termovisão, detecta as radiações infravermelhas emitidas pelos equipamentos inspecionados, transformado em imagens térmicas visíveis, chamadas de termogramas. Por meio dessas imagens são identificadas áreas quentes que são comparadas com as especificações do fabricante com o objetivo de analisar as reais condições de funcionamento do equipamento (MARQUES et al., 2013).

Além da constante necessidade de predizer e, até mesmo, prevenir as falhas em equipamentos em geral, há também a necessidade de incorporar nas empresas uma metodologia de manutenção autônoma. Assim, surgiu a manutenção produtiva total ou em inglês Total Productive Maintenance (TPM). A TPM surgiu no Japão após a Segunda Guerra Mundial, período no qual as empresas japonesas procuravam se reestabelecer por meio da excelência da qualidade de seus produtos que foi afetada, principalmente, pela grande destruição causada pela guerra (NOGUEIRA; GUIMARÃES; SILVA, 2012).

Já Fogliatto e Ribeiro (2011) descrevem em seu livro que a TPM está diretamente relacionada à qualidade dos produtos por meio da extinção da deterioração e mau desempenho dos maquinários ligados diretamente com a produção desses produtos. Os autores ainda afirmam que, para garantir isso, é necessário o envolvimento dos operadores, principalmente GEPROS. Gestão da Produção, Operações e Sistemas, v. 15, nº 2, p. 253 - 287, 2020. 
Confiabilidade de prensas excêntricas horizontais paralelas de uma linha de fabricação de embalagens metálicas para bebidas

por serem eles quem utilizam constantemente os equipamentos e possuem o conhecimento da real condição de operação dos maquinários, sendo capazes de sugerir e até mesmo aplicar manutenções de caráter primário.

A TPM é uma metodologia que engloba todo o efetivo da empresa, desde a gerência até os operários e clientes, incentivando e valorizando as pessoas para alcançar a melhoria contínua (NUNES, 2001). Mas, para identificar qual método será utilizado, em cada tipo de equipamento, a organização deverá possuir uma Gestão da Manutenção, que será assunto da próxima seção.

\subsection{Gestão da manutenção}

Marin et al. (2016, p. 139) afirmam que "os desenvolvimentos sociais e tecnológicos provocam a necessidade e dão a possibilidade para a evolução dos modelos de manutenção de gestão, e modelos de gestão em geral", sendo que a função da manutenção é "aumentar a eficácia e eficiência na prestação do serviço”. A gestão da manutenção tem como principal função ajudar a alcançar a otimização dos sistemas produtivos, por isso, cabe à ela decidir quais equipamentos serão reparados, definir quais métodos de manutenção são mais adequados a cada equipamento e qual a periodicidade que isso irá acontecer (SOUZA, 2008).

Costa (2013) afirma em seu estudo que para alcançar a eficiência, a gestão de manutenção deverá ter uma abordagem sistêmica. Para isso, essa forma de gestão deverá possuir gestores com excelente capacidade de liderar, focados nos valores da organização, com facilidade em aceitar mudanças e que consigam despertar em sua equipe um sentimento de ajuda mútua para a elaboração das tarefas de manutenção (COSTA, 2013).

Oliveira, Paiva e Paiva (2019, p. 72) discorrem que "a área de manutenção tem passado por mudanças importantes nas últimas décadas, orientada, principalmente, pela evolução dos conceitos gerenciais nas empresas", nas quais a manutenção deixou de ser sinônimo de gastos e passou a ser sinônimo de competitividade.

Os gestores da manutenção deverão focar em sempre deixar as máquinas que compõe os sistemas produtivos em perfeitas condições para que possam exercer seu trabalho, de modo a aumentar a confiabilidade nos processos produtivos, trazendo lucro e deixando a empresa competitiva no mercado (SOUZA, 2008).

Segundo Correia e Dias (2016, p. 267), “o custo de manutenção é fator decisivo na viabilidade operacional de um equipamento ou processo. Dentro do contexto industrial, o GEPROS. Gestão da Produção, Operações e Sistemas, v. 15, nº 2, p. 253 - 287, 2020 
Confiabilidade de prensas excêntricas horizontais paralelas de uma

linha de fabricação de embalagens metálicas para bebidas

custo de manutenção chega a representar, em média, 20\% dos custos fixos dos produtos". Para garantir a confiabilidade nos processos produtivos, a gestão da manutenção utiliza ferramentas de controle de qualidade e planeja com exatidão a periodicidade das intervenções de manutenção para cada tipo de maquinário, otimizado os custos e diminuindo as probabilidades de ocorrer falhas (CAIADO; LIMA; QUELHAS, 2015). Assim, pode-se observar que a gestão da manutenção é fundamental em qualquer processo produtivo.

\subsection{Manutenção centrada em confiabilidade}

Para Komninakis, Piratelli e Achcar (2018, p. 560) "a função manutenção tem um importante papel na busca por vantagens competitivas pelas empresas. Nesse sentido, a análise de confiabilidade de equipamentos é parte fundamental para a definição e seleção de estratégias de manutenção mais adequadas”. Moubray (2001) afirma que a manutenção centrada em confiabilidade (MCC) pode ser considerada como um processo utilizado para mostrar o que deve ser feito em um sistema industrial, assegurando que os itens físicos realizem suas funções.

A MCC é um método que surgiu na década de 1960 cuja origem foi movida pela necessidade de melhorar a confiabilidade dos equipamentos e garantir baixo custo de manutenção. Dessa forma, a indústria aérea americana desenvolveu as técnicas que constituem a MCC. Komninakis, Piratelli e Achcar (2018, p. 563) discorrem que a MCC apresenta "fatores cruciais para o sucesso das empresas" e que "altos custos motivam a busca por soluções de engenharia que aumentem a confiabilidade, reduzam gastos financeiros".

Além disso, a MCC pode ser descrita como uma ferramenta que utiliza vários métodos de engenharia para garantir a disponibilidade das máquinas e sistemas produtivos. Por possuir técnicas lógicas e ordenadas, a MCC possibilita uma gestão da manutenção eficiente, fazendo com que as intervenções de manutenções sejam enxutas, diminuindo os custos dos reparos e evitando paradas inesperadas da produção (FOGLIATTO; RIBEIRO, 2011).

Fogliatto e Ribeiro (2011) ressaltam que para uma MCC eficaz é necessário que a equipe de manutenção tenha o entendimento de quais são as reais funções do equipamento, qual seu padrão de funcionamento e qual é sua vida útil. Nesse sentindo, deve-se compreender que os equipamentos que compõe um sistema produtivo possuem duas funções distintas: realizar o trabalho para qual foi destinado e executar esse trabalho com eficiência. Por meio desse entendimento é que se pode ter um sentido para a MCC. 
Confiabilidade de prensas excêntricas horizontais paralelas de uma

linha de fabricação de embalagens metálicas para bebidas

A metodologia da MCC enfatiza a utilização de atuações ágeis na resolução dos defeitos em equipamentos. Para isso é utilizado um diagrama que analisa os modos de falhas e, ao ser identificada uma possível falha, indica o melhor método de manutenção a ser empregado, baseando em ações reativas que possuem efeito imediato na resolução do defeito e nas ações proativas que previnem as causas das falhas (FOGLIATTO; RIBEIRO, 2011).

Para chegar à excelência, a MCC deverá evoluir junto com o projeto do equipamento dentro da empresa, pois só assim terá as informações necessárias para conservar suas funções e direcionar a ação de manutenção mais adequada (SOUZA, 2008).

Com a escolha correta das ações, a MCC alcança a qualidade e disponibilidade dos processos produtivos, tornando-se critério para a obtenção da certificação ISO 9001, visto que suas metodologias tornam os procedimentos mais organizados, efetivos e rastreáveis, garantindo, assim, a excelência do trabalho (LUCATELLI, 2002). Calache et al. (2019) acrescentam que outro critério importante para alcançar a qualidade é a escolha da manutenção industrial, que deve ser bem escolhida e contar com funcionários devidamente treinados, o que evita maiores custos no processo.

Lucatelli (2002) contribui afirmando que, após a constatação da falha, a MCC utiliza ferramentas para identificar quais os tipos de falhas, suas causas e definir seus efeitos. Essa ferramenta é chamada de Análise dos Modos de Falha e seus Efeitos, em inglês Failure Mode and Effect Analysis (FMEA). De acordo com a norma 5462 (ABNT, 1994), FMEA é uma ferramenta de confiabilidade que avalia qualitativamente as medidas de confiabilidade que abrangem os modos de falha de certo componente de um equipamento e suas consequências sobre o funcionamento dos outros componentes e sobre o funcionamento do conjunto como um todo.

Lucatelli (2002), refere-se a outro modelo de análise da confiabilidade, a Análise da Árvore de Panes (Fault Tree Analysis - FTA). A norma 5462 (ABNT, 1994) define a FTA como um modelo matemático que analisa os modos de panes por meio de um modelo de árvore de panes, para definir quais os tipos de defeitos presentes em um subcomponente de um equipamento e quais os fatos externos que resultam em tal defeito.

Pode-se entender que a utilização da metodologia MCC não dispensa os outros modelos de manutenção, pelo contrário, após a identificação das possíveis falhas a MCC age em conjunto com as outras metodologias para destinar ações de reparo e prevenção. 
Confiabilidade de prensas excêntricas horizontais paralelas de uma linha de fabricação de embalagens metálicas para bebidas

\subsection{Confiabilidade de equipamentos industriais}

A confiabilidade foi incluída na manutenção por meio de um estudo inovador sobre defeitos em equipamentos eletrônicos de uso da aeronáutica dos Estados Unidos da América realizado por uma equipe de pesquisadores da Federal Aviation Administration. Tal estudo mudou a visão de como era executado os procedimentos de manutenção (MOUBRAY, 2001).

Nesse contexto, confiabilidade pode ser definida como a habilidade de um componente cumprir seu papel estabelecido dentro de condições especificadas durante um espaço de tempo determinado e sem apresentar falhas (ABNT, 1994). De acordo com essa definição, a confiabilidade é um termo usado para estipular a probabilidade que um determinado componente pode executar sua função sem apresentar falhas, desde que tenha um tempo de operação e condições de uso bem definidos.

Também há duas formas de disponibilidade: física e intrínseca. Ambas serão abordadas nas seções seguintes.

\subsubsection{Disponibilidade física}

Disponibilidade física é a possibilidade de um item ficar em operação durante um tempo definido, sem apresentar falhas, sendo obtida por meio da Equação (1) apresentada a seguir. Nessa equação é calculado a relação entre o tempo determinado de operação e o tempo que realmente o equipamento esteve disponível (BRANCO FILHO, 2000).

$$
\mathrm{DF}=\frac{\mathrm{HD}-\mathrm{HM}}{\mathrm{HD}}
$$

$$
\begin{aligned}
& \text { Sendo que: } \\
& \text { DF - É o tempo de disponibilidade física } \\
& \text { HD - É o tempo disponível } \\
& \text { HM - É o tempo que o equipamento está em manutenção }
\end{aligned}
$$

O cálculo expressa a relação entre o tempo em que um equipamento ou instalação industrial está disponível para operação e o total de horas especificadas no projeto para o período. 
Confiabilidade de prensas excêntricas horizontais paralelas de uma linha de fabricação de embalagens metálicas para bebidas

\subsubsection{Disponibilidade intrínseca}

Disponibilidade intrínseca está relacionada com o tempo médio entre falha (Mean Time Between Failure - MTBF) e o tempo médio para reparo (Mean Time To Repair MTTR), a qual é obtida por meio da quantidade de intervenções realizadas pela manutenção, criando um índice de disponibilidade do equipamento (BRANCO FILHO, 2000). Tal disponibilidade é calculada pela seguinte Equação (2):

$$
\mathrm{DI}=\left(\frac{\mathrm{MTBF}}{\mathrm{MTBF}+\mathrm{MTTR}}\right) \times 100
$$

Sendo que:

DI - É a disponibilidade intrínseca

MTBF - É o tempo médio para reparo

MTTR - É o tempo médio para reparo

Selitto (2007, p. 99) assevera que esse "parâmetro pode realimentar o projeto de equipamentos complexos e instalações industriais, pois, além da resistência ao processo de falha, apreendida no MTBF, considera a facilidade de reparo, apreendida no MTTR".

\subsubsection{Tempo médio para reparo}

O tempo médio para reparo é um apontador para avaliar a média de tempo gasto para reparar um equipamento ou máquina. Sendo que, quanto menor for esse tempo, melhor para o processo, pois o sistema terá menos tempo indisponível (SELLITTO, 2007). Esse MTTR é calculado por meio da seguinte Equação (3):

$\operatorname{MTTR}=\frac{\text { HPC }}{\text { PC }}$

Sendo que:

MTTR - É o tempo médio para reparo

HPC - É a quantidade de horas por paradas corretivas

PC - É a quantidade de paradas corretivas 
Confiabilidade de prensas excêntricas horizontais paralelas de uma linha de fabricação de embalagens metálicas para bebidas

Segundo Sellitto (2007, p. 107), “o MTTR indica a eficiência na ação corretiva de um processo, o esforço deve ser exatamente o contrário do MTBF, menor tempo médio de reparo indica que a manutenção possui respostas rápidas para problemas em seus processos”.

\subsubsection{Tempo médio entre falha}

O tempo médio entre falha, ao contrário do MTTR, mede o tempo que o equipamento ou máquina opera sem apresentar falhas. Quanto maior o MTBF for, melhor para o sistema, pois isso significa maior disponibilidade dos componentes para operação (SELLITTO, 2007). Esse tempo é calculado pela seguinte da Equação (4):

$$
\mathrm{MTBF}=\frac{\mathrm{HO}}{\mathrm{FP}}
$$

Sendo que:

MTBF - É o tempo médio entre falha

HO - São as horas de operação sem falhas

FP - É a quantidade de falhas nesse período de operação

Com base nos resultados obtidos com os cálculos do MTBF, do MTTR e da disponibilidade, pode-se verificar a confiabilidade do processo produtivo, pois ela depende principalmente da disponibilidade de seus maquinários.

\subsubsection{Cálculo da confiabilidade}

Confiabilidade é a perspectiva de um definido conjunto, subconjunto, equipamento ou sistema produtivo cumprir a sua função explicitada no projeto, dentro de condições de operação e período de tempo estabelecido. Ou seja, sempre que confiabilidade for mencionada, ela deve ser vinculada a um intervalo de tempo. Então, é correto afirmar que a confiabilidade de um equipamento é a probabilidade de este funcionar conforme suas especificações de projeto, por exemplo, são de 99,8\% nas próximas 5.000 horas (TELLES, 2017).

Telles (2017) apresenta que a confiabilidade está relacionada ao futuro, é uma projeção probabilística que indica as chances de o maquinário operar sem falhas em um 
Confiabilidade de prensas excêntricas horizontais paralelas de uma linha de fabricação de embalagens metálicas para bebidas

intervalo de tempo definido. Sendo assim, para calcular a confiabilidade individual, primeiramente calcula-se a taxa de falhas ( $\lambda$ ) utilizando a Equação (5), posteriormente, utilizando o resultado obtido nessa equação, calcula-se a confiabilidade individual (R) dos equipamentos utilizando a Equação (6).

$$
\begin{aligned}
& \lambda(t) \frac{1}{M T B F} \\
& R(t)=e^{-\gamma t}
\end{aligned}
$$

Encontrado a confiabilidade individual, calcula-se a confiabilidade do sistema. No estudo de Teles (2017) foi utilizado o arranjo em paralelo, como mostra a Figura 2, pois nos sistemas em paralelo a confiabilidade aumenta por haver outras máquinas que servirão de estepe em caso de uma falha. Para tal cálculo, utiliza-se a Equação (7).

Figura 2 - Sistemas em Paralelo

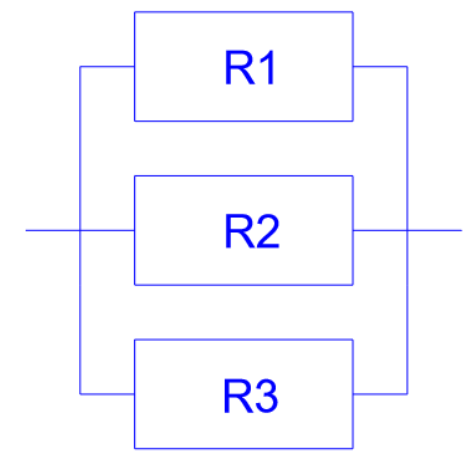

Fonte: Adaptado de Talles (2017).

Paralelo $=1-(1-\mathrm{R}(\mathrm{n}))$

Pelo fato do objeto de estudo ser uma prensa excêntrica, ela será o assunto da próxima seção. 
Confiabilidade de prensas excêntricas horizontais paralelas de uma linha de fabricação de embalagens metálicas para bebidas

\subsection{Prensa excêntrica}

A prensa é um equipamento em que a matéria-prima é trabalhada por meio de conformação ou de corte e é utilizada, especialmente, na metalurgia básica. A prensa é usada para conformar, moldar, cortar, furar, cunhar e vazar peças. Nesses processos, existe sempre uma punção movimentada por um cilindro hidráulico (prensa hidráulica) ou por um sistema mecânico (prensa excêntrica) em que o movimento de giro proveniente de um motor elétrico é modificado em retilíneo alternado por meio de um sistema de biela, virabrequim e fuso (MANSANO, 2008).

Azevedo (2003) define uma prensa mecânica como uma máquina capaz de transmitir força e/ou deslocamento ao conjunto de ferramentas com o intuito de moldar a matéria-prima de modo a obter o formato desejável, sendo que a força e movimento em prensas mecânicas são gerados por meio da concentração de energia do volante que gira em falso sobre um eixo. Quando a embreagem é conectada ao eixo principal da prensa, ela conduz o movimento por meio de um sistema composto por bielas, virabrequim e eixo que, por sua vez, está fixado a ferramenta.

A prensa excêntrica pode ser de acionamento por chaveta ou por freio/embreagem. Já a prensa mecânica excêntrica de acionamento por chaveta possui como propriedade o deslocamento restrito, potência constante e força variável da punção de acordo com a distância de serviço. Ela pode possuir a estrutura em forma de "C" com um esteio ou em forma de "H" com duplo esteio, com transferência de movimento direto do volante ou com redução por engrenagens, com mesa fixa ou ajustável, horizontal ou inclinada. O volante, movimentado por um motor elétrico, está apoiado na extremidade de um eixo, através de uma bucha de engate na qual se encaixa uma chaveta rotativa (SALVI et al., 2014).

A carcaça da prensa é arquitetada para suportar todos os esforços operantes sobre a máquina. A estrutura da prensa é projetada de acordo com os esforços de estampagem, que define a robustez estrutural dos tamanhos das ferramentas, das restrições de acesso do local onde será instalada e do nível de orientação e exatidão requerido pela punção (AZEVEDO, 2003).

A Figura 3 ilustra um exemplo de prensa mecânica excêntrica com acionamento por chaveta de simples efeito com os elementos que constituem a estrutura, tais como cabeçote, colunas, martelo, matrizes superior e inferior e base. 
Figura 3 - Prensa Mecânica Excêntrica de Acionamento por Chaveta

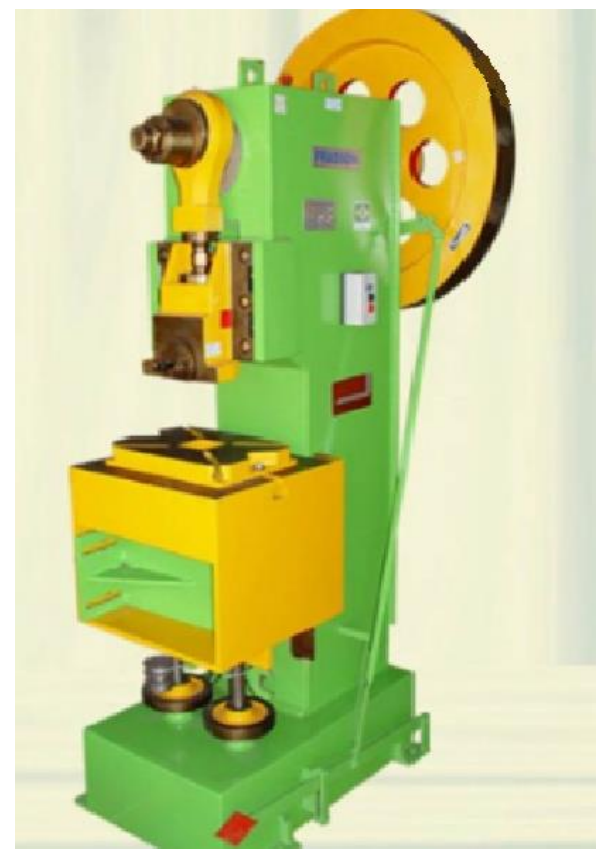

Fonte: Salvi et al. (2014, p. 6).

Já a prensa de acionamento por freio/embreagem possui um funcionamento transmitido pelo movimento de rotação de um motor elétrico para o volante que gira livre sobre o eixo árvore ou eixo intermediário que, quando apertados os botões do comando bi manual de simultaneidade ou acionamento eletrônico (CLP), recebe o comando da válvula pneumática de segurança, deixando a passagem do ar, que acopla o sistema de embreagem transmitindo o movimento rotativo do volante para o eixo. Por sua vez, com movimento de rotação do eixo, o conjunto da biela/excêntrico movimenta a punção da prensa no sentido vertical para executar o trabalho (SALVI et al., 2014).

A prensa com acionamento por freio/embreagem é um equipamento totalmente confiável, pois pode ser desativada a qualquer momento não importando qual posição a punção se encontra ao contrário da prensa de acionamento por chaveta que, ao ser acionada, só para quando completa o ciclo de descida e subida da punção. Esse tipo de prensa possui alto custo de instalação, necessidade de manutenções preventivas e possui um certo nível de complexidade em seus conjuntos mecânicos e de acionamento (MANSANO, 2008). A Figura 4 ilustra uma prensa com acionamento por freio/embreagem. 
Confiabilidade de prensas excêntricas horizontais paralelas de uma linha de fabricação de embalagens metálicas para bebidas

Figura 4 - Prensa Mecânica Excêntrica com Acionamento por Freio/Embreagem

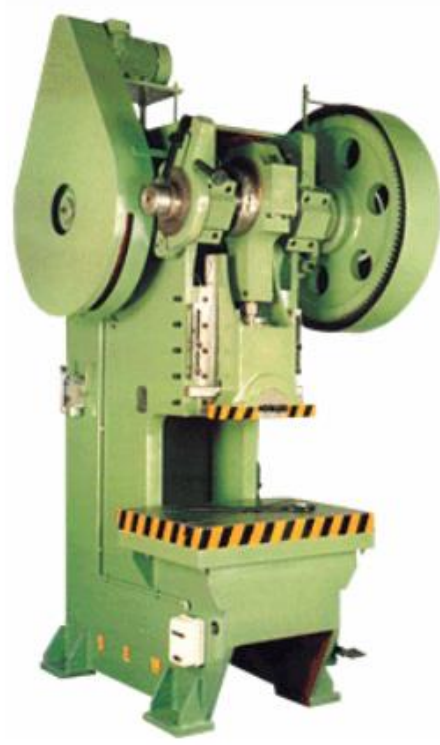

Fonte: Salvi et al. (2014, p. 6).

Esses tipos de prensas são utilizados principalmente na estampagem de peças metálicas para indústria automotiva e para utensílios domésticos e sua configuração horizontal é largamente utilizada em indústrias de fabricação de embalagem metálicas para bebidas.

\subsection{Prensa excêntrica horizontal}

A presa excêntrica horizontal em estudo possui as mesmas características básicas das prensas verticais já referenciadas. O que difere é o plano geométrico em que sua ferramenta (punção) trabalha, no caso, seu movimento retilíneo alternado é realizado no plano horizontal. É uma máquina de funcionamento contínuo que tem por finalidade transformar uma préforma, denominada copo, em um corpo de lata (STOLLE MACHINERY, 2016).

No layout operacional típico, a prensa excêntrica horizontal recebe copos de um sistema de transporte, transforma os copos em corpos de latas por meio de uma operação contínua de laminação e prensagem da parede (processo de estiramento) e transfere os corpos de lata por meio de um transportador de saída para a alimentação de outra máquina, a aparadora de bordas. A máquina é projetada para produzir corpos de lata de vários tamanhos em alumínio ou aço, em condições operacionais adequadas, de forma automática e contínua, sendo desligada automaticamente quando algum defeito causa congestionamento ou produção de corpo de latas com defeitos (STOLLE MACHINERY, 2016). 
Confiabilidade de prensas excêntricas horizontais paralelas de uma linha de fabricação de embalagens metálicas para bebidas

Sua velocidade normal de trabalho está entre 300 e 450 latas por minuto e seu funcionamento é controlado por um comando lógico programável (CLP) que fornece a característica de funcionamento completamente automático a esta prensa (STOLLE MACHINERY, 2016). A prensa excêntrica horizontal é um sistema integrado composto por uma formadora básica, um console elétrico de controle e um sistema de lubrificação, como apresentado na Figura 5.

Figura 5 - Prensa Excêntrica Horizontal em Estudo

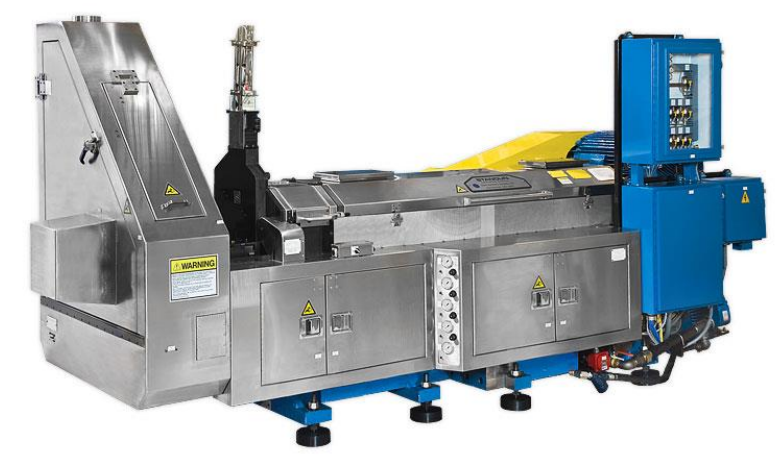

Fonte: Adaptado de Stolle Machinery (2016).

A prensa excêntrica horizontal é uma máquina de conformação mecânica sequencial multifuncional de trabalho pesado e ação dupla. Ela conforma corpos de lata não recortados com tolerâncias extremamente rigorosas e por longos ciclos de produção contínuos. A máquina foi projetada para funcionar com atenção e manutenção mínimas do operador (STOLLE MACHINERY, 2016).

A prensa possui um sistema de tomada de força, originada de um motor elétrico que transfere movimento circular para um volante este, por sua vez, está ligado a um sistema de embreagem/freio que ao ser acoplado transfere o movimento para um eixo excêntrico (virabrequim), que por meio de um conjunto de bielas transforma o movimento circular em retilíneo alternado, essencial para o processo de conformação da lata (STOLLE MACHINERY, 2016). A Figura 6 apresenta um desenho técnico da prensa excêntrica horizontal, mostrando as principais partes e conjuntos mecânico, elétrico, hidráulico e pneumático que compõem a máquina. 
Confiabilidade de prensas excêntricas horizontais paralelas de uma linha de fabricação de embalagens metálicas para bebidas

Figura 6 - Localização dos Principais Componentes da Prensa
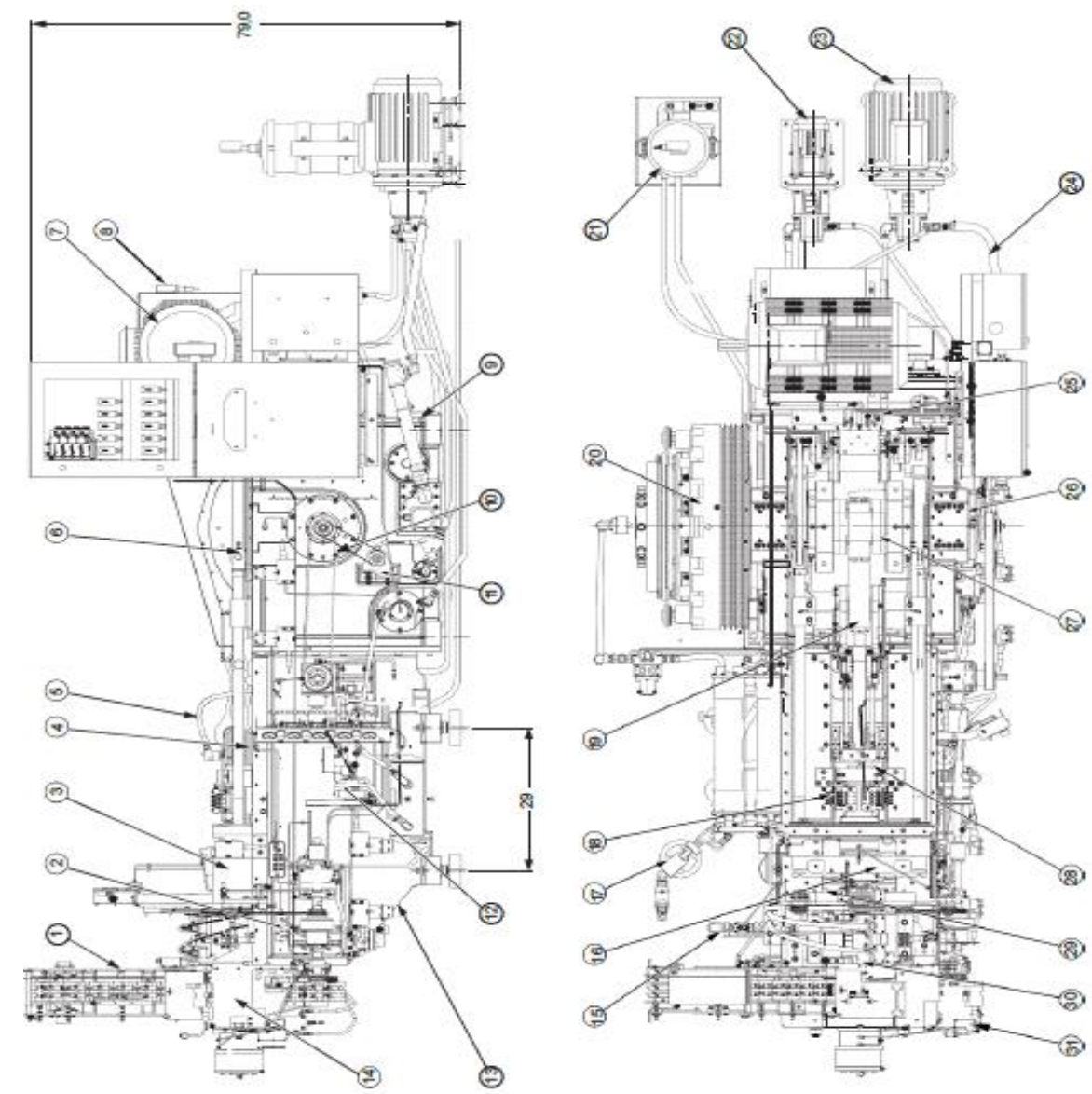

Fonte: Adaptado de Stolle Machinery (2016).

\subsection{Processo de fabricação de latas de alumínio para bebidas}

O processo de fabricação de latas de alumínio para bebidas é dividido nas etapas seguintes: formação do copo; formação do corpo e apara da lata; lavagem e secagem; impressão do rótulo e revestimento externo; secagem, cura e aplicação do revestimento interno; formação do pescoço e flange; controle de qualidade; e paletização (ABRALATAS, 2018).

A formação do copo é realizada por uma lâmina de alumínio fornecida em formato de enormes bobinas. Essa chapa de alumínio é inserida em uma prensa excêntrica vertical (copper) que possui um conjunto de fermentas, com a finalidade de estampar milhares de copos rasos por minuto, esse processo é denominado conformação mecânica. Após a formação do copo, ele segue por uma mesa de ar que o transporta até o próximo processo (ABRALATAS, 2018). 
Confiabilidade de prensas excêntricas horizontais paralelas de uma linha de fabricação de embalagens metálicas para bebidas

A formação do corpo da lata é feita por um processo mecânico denominado estiramento, sendo realizado por uma prensa excêntrica horizontal. Nesse processo, o copo raso desce por gravidade através de um conveio para alimentar a máquina que, por sua vez, submete o copo através de prensagem a passar por vários anéis calibrados (matrizes) com diâmetros escalonados, fazendo com que a espessura da parede diminua e vai alongando seu corpo gradativamente. Após a formação do corpo, a lata é transferida para outra máquina (trimmer) que apara sua borda irregular, deixando a lata com a altura nominal especificada pelo cliente (ABRALATAS, 2018).

A lata já formada e aparada é transportada por uma esteira transportadora para o processo seguinte, a lavagem química (washer) interna e externa de alta eficiência que proporciona a retirada de fragmentos e detritos originados no processo de formação do corpo, passando depois por um forno de secagem. Após esta etapa, as latas já estão prontas para receber a impressão de seus rótulos (ABRALATAS, 2018).

A impressão do rótulo ocorre por um processo de litografia que pode utilizar até oito cores sobrepostas na lata em um único deslocamento. Posteriormente e quase que ao mesmo tempo, a lata ganha uma camada externa de verniz incolor para dar melhor acabamento e brilho, além de evitar que a tinta descasque, e outra camada no fundo para garantir a mobilidade da lata (ABRALATAS, 2018).

As latas já rotuladas passam por um forno, agora com o intuito de curar o verniz de proteção externa. Em seguida, é aplicado o verniz interno que forma um revestimento de proteção na parte interna da lata. Esse procedimento é realizado para garantir que o líquido envasado não entre em contato com a superfície metálica, evitando algum tipo de oxidação ou alteração no sabor da bebida. As latas, então, são levadas novamente a um forno para secagem e cura do verniz interno (ABRALATAS, 2018).

Após a cura e secagem, o corpo de lata passa para o processo de formação do pescoço (necker), no qual a extremidade aberta do corpo é submetida a uma pressão que diminui o diâmetro da abertura, formando o pescoço e o perfil da borda (flange) para encaixe da tampa. Ao ser feito esse processo, e ainda dentro da mesma máquina, é realizado uma inspeção de qualidade utilizando um equipamento (câmera) que identifica qualquer anomalia nas latas e as expulsam do processo que, posteriormente, serão direcionadas para a reciclagem (ABRALATAS, 2018). 
Confiabilidade de prensas excêntricas horizontais paralelas de uma linha de fabricação de embalagens metálicas para bebidas

As latas agora prontas e já inspecionadas são embaladas para armazenagem e transporte, empilhadas em pallets. A Figura 7 demonstra todos os processos de fabricação da lata de alumínio para bebidas.

Figura 7 - Layout do Processo de Fabricação de Latas de Alumínio para Bebidas

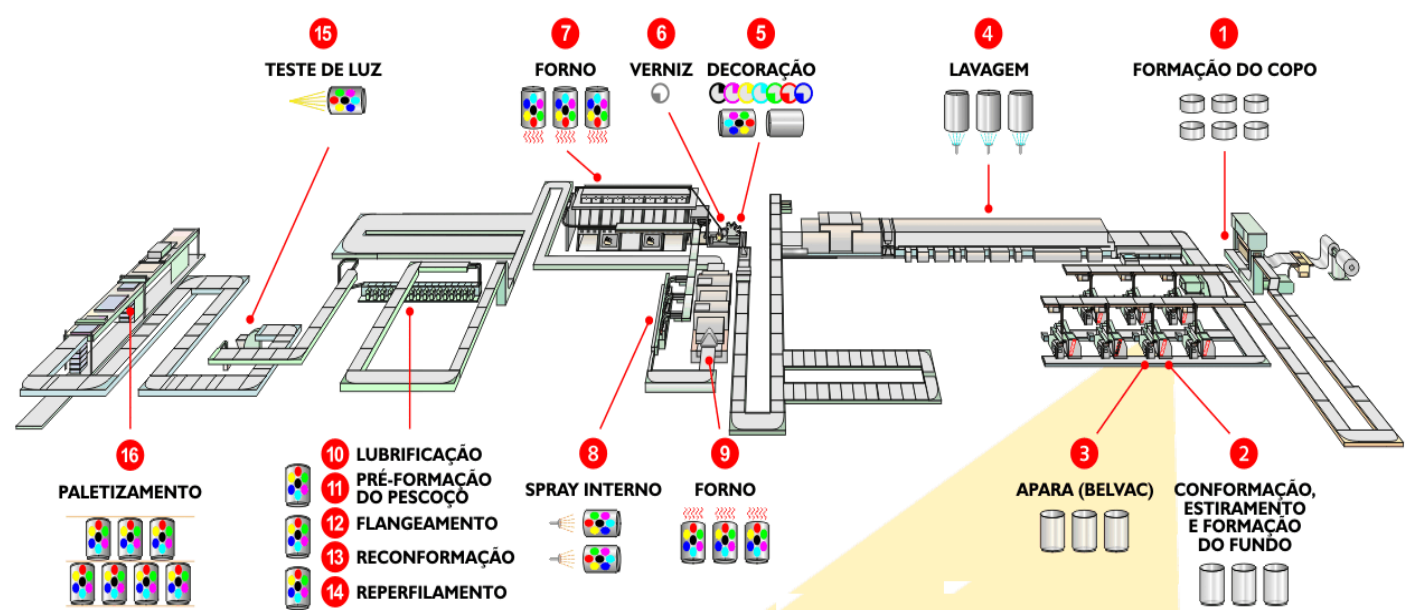

Fonte: Adaptado ABRALATAS (2018).

O processo de fabricação de latas de alumínio para bebidas obedece ao Layout em linha, como vista na Figura 7, na qual os processos são subsequentes uns aos outros, ou seja, ao final de um estágio o produto é passado para outro estágio, até que fique totalmente pronto.

\section{PROCEDIMENTOS METODOLÓGICOS}

Este estudo, no que tange aos objetivos, foi conduzido por meio de uma pesquisa descritiva. Quanto aos procedimentos, este estudo utilizou a abordagem quantitativa. Foram utilizados os cálculos de confiabilidade como mecanismo estatístico para modelar os dados obtidos durante a pesquisa e diagnosticar a real condição dos equipamentos em estudo. Para organização e modelagem dos dados foi utilizado o Software Excel 2013®. A coleta de dados foi feita por meio da pesquisa documental cedida pela empresa em estudo.

O estudo foi realizado em uma multinacional do ramo de embalagens metálicas, situada no interior do estado de Goiás. Foi escolhido um conjunto de nove prensas excêntricas horizontais dispostas em paralelo do setor de estamparia. Estas máquinas são primordiais para o processo e realizam a operação inicial, então sem o bom funcionamento das mesmas o 
Confiabilidade de prensas excêntricas horizontais paralelas de uma linha de fabricação de embalagens metálicas para bebidas

restante do processo será prejudicado. Foi realizado um relato técnico da aplicação de indicadores de manutenção num ambiente de manufatura.

A coleta de dados foi autorizada pela empresa mediante um acordo de confidencialidade, por isso será tratada como Empresa X. Realizou-se uma pesquisa no software de gerenciamento de manutenção da empresa no período de 01/11/2017 a 20/10/2018, a fim de buscar e quantificar as três principais falhas já ocorridas que ocasionaram paradas das máquinas. Criou-se uma planilha na qual foi inserido, de forma organizada, os dados coletados de modo a facilitar a análise. Na planilha consta: o tipo de falha - se é mecânica ou elétrica -, o conjunto ou subconjunto que falhou, o tempo gasto para reparar a falha e o tempo até a falha.

Após a organização dos dados, na quarta etapa, foram calculados o MTBF, o MTTR, a disponibilidade e a confiabilidade, conforme a quantidade de falhas e paradas. Alcançadas as confiabilidades dos maquinários individuais, calculou-se a confiabilidade do sistema, o que está relacionado conforme a maneira que as máquinas estão dispostas. Apesar de haver outras formas de arranjos, duas são satisfatórias para expor a maioria dos sistemas industriais: a conexão série e a conexão paralela.

No presente trabalho, calculou-se os itens descritos acima de nove prensas excêntricas horizontais que compõe uma linha de produção de latas de alumínio para bebidas. Essas máquinas obedecem ao arranjo paralelo. A conexão paralela é caracterizada pela disposição das máquinas paralelamente uma da outra, sendo que uma não depende da outra para funcionar. Já o arranjo em série tem um processo contrário, nele existe apenas uma entrada do sistema e a saída de uma máquina se torna a entrada da outra e, quando uma para de funcionar, a outra automaticamente também para.

Sequencialmente foi realizada a análise dos resultados obtidos pelos cálculos a fim de diagnosticar a real disponibilidade das máquinas e indicar uma metodologia de manutenção eficaz. 
Confiabilidade de prensas excêntricas horizontais paralelas de uma linha de fabricação de embalagens metálicas para bebidas

\section{RESULTADOS E DISCUSSÕES}

O estudo foi realizado em uma multinacional fabricante de lata de alumínio para bebidas. Por motivo estratégico a empresa fez um acordo de confidencialidade para que o estudo fosse feito, por isso, tal fábrica será tratada como Empresa X.

A Empresa $X$ faz parte de um grupo que tem operado no mercado de embalagens de metal por mais de 25 anos. Durante este período, tornou-se uma fabricante líder na indústria de embalagens para bebidas na Europa, constantemente melhorando a sua posição no mercado do Oriente Médio, Ásia, África, e América do Sul. Em 2017, adquiriu uma fábrica localizada no litoral brasileiro e construiu outra no interior do Brasil.

Como consequência dos investimentos contínuos e a instalação de equipamentos de um nível tecnológico de classe mundial, a capacidade e variedade das embalagens e serviços oferecidos tem crescido dinamicamente, tornando o processo de produção ajustado aos padrões técnicos mais elevados do mundo. Tudo isso em combinação com uma perfeição estética e uma estrutura flexível de vendas, que se traduzem em segurança e profissionalismo, representando um elevado nível de serviço para os clientes.

Atualmente a Empresa $\mathrm{X}$ possui 17 linhas de produção de latas de alumínio para bebidas e 16 linhas de tampas em 12 unidades de produção em 10 países. A empresa possui capacidade de produção de 15,5 bilhões de latas para bebidas e tampas por ano. Também operam 2 fábricas de embalagens de vidro, 7 fábricas de tampa tipo coroa e 3 fábricas que produzem latas de aço de 3 peças, possuindo mais de 4.500 colaboradores globalmente.

A coleta de dados foi realizada em uma planta de fabricação de latas de alumínio para bebidas, onde foi realizada uma pesquisa no software de gerenciamento de manutenção da empresa. Esta pesquisa possui um tempo determinado que começa com início das operações da plana, visto que é uma empresa nova, com cerca de um ano de operação. Os dados foram coletados entre as datas 01/11/2017 e 20/10/2018, possuindo um intervalo de tempo de quase um ano.

A condição básica para a realização da análise de falhas é que exista um banco de dados com informações de manutenção suficientes e factíveis. Dessa forma, analisou-se os históricos de manutenções realizados nas nove prensas excêntricas horizontais que compõem uma das linhas de produção. Após a pesquisa no software, constatou-se que havia várias ocorrências de falhas, onde três se destacaram pela quantidade superior de ocorrência e por GEPROS. Gestão da Produção, Operações e Sistemas, v. 15, nº 2, p. 253 - 287, 2020. 
Confiabilidade de prensas excêntricas horizontais paralelas de uma linha de fabricação de embalagens metálicas para bebidas

sua criticidade, pois todas resultaram em paradas das máquinas para manutenções corretivas. Foram, então, coletados e relacionados os dados referentes às falhas: falha no sensor de lata pronta, no sensor de lata curta e na válvula pneumática de extração da lata, tais falhas foram escolhidas por serem recorrentes.

Visto que a empresa ainda não possui uma gestão efetiva de manutenção, os dados referentes aos atos de manutenção nas máquinas e equipamentos foram inseridos de forma desorganizada no software, então foi necessário organizá-los em uma tabela, como mostra a Tabela 1 a seguir.

Tabela 1 - Relação das Falhas nas Prensas Excêntricas Horizontais

\begin{tabular}{|c|c|c|c|c|c|c|}
\hline \multicolumn{7}{|c|}{ Manutenção das Prensas Excêntricas Horizontais } \\
\hline Prensa & $\begin{array}{l}\text { Tipo de } \\
\text { Falha } \\
\end{array}$ & Conjunto/Subconjunto & Período & Quant. & $\begin{array}{c}\text { Tempo para } \\
\text { Reparo/horas }\end{array}$ & $\begin{array}{c}\text { Horas de } \\
\text { Manutenção } \\
\end{array}$ \\
\hline \multirow{3}{*}{ P01 } & \multirow{2}{*}{ Elétrica } & Sensor de Lata Pronta & \multirow{3}{*}{$\begin{array}{c}01 / 11 / 2017 \text { a } \\
20 / 10 / 2018\end{array}$} & 10 & 25 & \multirow{3}{*}{109} \\
\hline & & Sensor de lata Curta & & 8 & 24 & \\
\hline & Mecânica & Válvula Pneumática de extração & & 15 & 60 & \\
\hline \multirow{3}{*}{$\mathrm{P} 02$} & \multirow{2}{*}{ Elétrica } & Sensor de Lata Pronta & \multirow{3}{*}{$\begin{array}{c}01 / 11 / 2017 \text { a } \\
20 / 10 / 2018\end{array}$} & 8 & 20 & \multirow{3}{*}{88} \\
\hline & & Sensor de lata Curta & & 11 & 33 & \\
\hline & Mecânica & Válvula Pneumática de extração & & 9 & 35 & \\
\hline \multirow{3}{*}{$\mathrm{P} 03$} & \multirow{2}{*}{ Elétrica } & Sensor de Lata Pronta & \multirow{3}{*}{$\begin{array}{c}01 / 11 / 2017 \mathrm{a} \\
20 / 10 / 2018\end{array}$} & 10 & 25 & \multirow{3}{*}{90} \\
\hline & & Sensor de lata Curta & & 9 & 27 & \\
\hline & Mecânica & Válvula Pneumática de extração & & 10 & 38 & \\
\hline \multirow{3}{*}{$\mathrm{P} 04$} & \multirow{2}{*}{ Elétrica } & Sensor de Lata Pronta & \multirow{3}{*}{$\begin{array}{c}01 / 11 / 2017 \mathrm{a} \\
20 / 10 / 2018\end{array}$} & 5 & 13 & \multirow{3}{*}{75} \\
\hline & & Sensor de lata Curta & & 7 & 21 & \\
\hline & Mecânica & Válvula Pneumática de extração & & 12 & 41 & \\
\hline \multirow{3}{*}{ P05 } & \multirow{2}{*}{ Elétrica } & Sensor de Lata Pronta & \multirow{3}{*}{$\begin{array}{c}01 / 11 / 2017 \text { a } \\
20 / 10 / 2018\end{array}$} & 9 & 23 & \multirow{3}{*}{83} \\
\hline & & Sensor de lata Curta & & 10 & 30 & \\
\hline & Mecânica & Válvula Pneumática de extração & & 8 & 30 & \\
\hline \multirow{3}{*}{ P06 } & \multirow{2}{*}{ Elétrica } & Sensor de Lata Pronta & \multirow{3}{*}{$\begin{array}{c}01 / 11 / 2017 \mathrm{a} \\
20 / 10 / 2018\end{array}$} & 8 & 20 & \multirow{3}{*}{93} \\
\hline & & Sensor de lata Curta & & 9 & 27 & \\
\hline & Mecânica & Válvula Pneumática de extração & & 12 & 46 & \\
\hline \multirow{3}{*}{ P07 } & \multirow{2}{*}{ Elétrica } & Sensor de Lata Pronta & \multirow{3}{*}{$\begin{array}{c}01 / 11 / 2017 \mathrm{a} \\
20 / 10 / 2018\end{array}$} & 10 & 25 & \multirow{3}{*}{72} \\
\hline & & Sensor de lata Curta & & 6 & 18 & \\
\hline & Mecânica & Válvula Pneumática de extração & & 8 & 29 & \\
\hline \multirow{3}{*}{ P08 } & \multirow{2}{*}{ Elétrica } & Sensor de Lata Pronta & & 6 & 15 & \\
\hline & & Sensor de lata Curta & $01 / 11 / 2017$ a & 7 & 21 & 59 \\
\hline & Mecânica & Válvula Pneumática de extração & & 6 & 23 & \\
\hline & Flétrica & Sensor de Lata Pronta & & 8 & 20 & \\
\hline P09 & Eletrica & Sensor de lata Curta & $01 / 11 / 2017 \mathrm{a}$ & 5 & 15 & 79 \\
\hline & Mecânica & Válvula Pneumática de extração & & 12 & 44 & \\
\hline & & & Total/Horas & 238 & & 747 \\
\hline
\end{tabular}

Fonte: Dados da pesquisa.

A Tabela 1 mostra de forma organizada a relação das três principais falhas ocorridas no período analisado, levando em consideração o tipo da falha (mecânica ou elétrica), o componente que apresentou a falha, a quantidade de vezes que ocorreu e o tempo de reparo de 
Confiabilidade de prensas excêntricas horizontais paralelas de uma linha de fabricação de embalagens metálicas para bebidas

cada falha. Vale salientar que os resultados foram criados com base na teoria desenhada no referencial teórico, que foi suporte para os cálculos.

Com base na Tabela 1 foi possível gerar um gráfico demonstrando qual falha teve maior ocorrência e que deixou a máquina inoperante, ou seja, foi possível identificar a falha que mais impactou no processo de produção, como mostra o Gráfico 1.

Gráfico 1 - Tempo de Parada por Falha

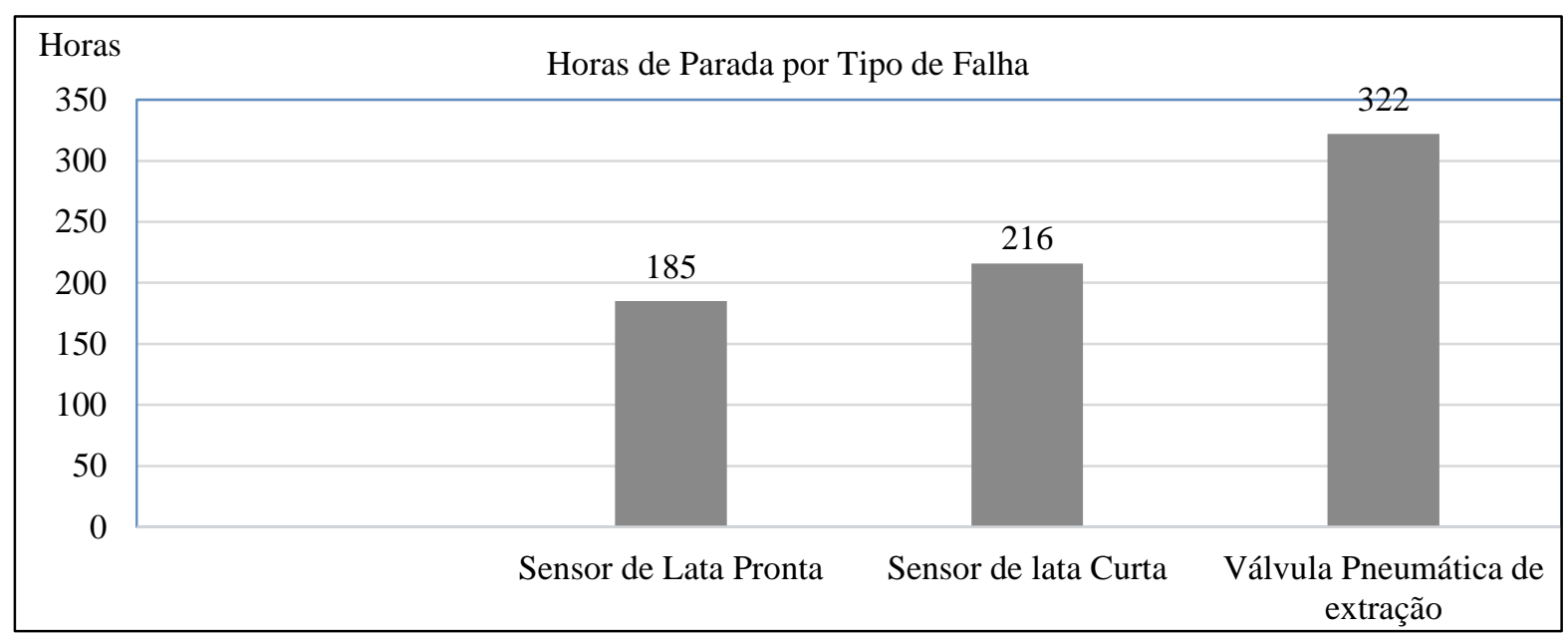

Fonte: Dados da pesquisa.

Analisando o gráfico, notou-se que a falha com o maior impacto sobre o funcionamento das prensas foi a da válvula pneumática de extração da lata. Então, como a confiabilidade de um equipamento é tal quanto a de seus componentes, foram utilizados apenas os dados referentes a esse componente para os cálculos de confiabilidade.

Ainda foi possível gerar outro gráfico que demonstra qual prensa excêntrica horizontal teve o maior número de paradas, levando em consideração as três falhas, como mostra o Gráfico 2. Com o respectivo gráfico (Gráfico 2) é possível ampliar o entendimento e a assertividade das estratégias futuras. 
Confiabilidade de prensas excêntricas horizontais paralelas de uma linha de fabricação de embalagens metálicas para bebidas

Gráfico 2 - Históricos de Tempo até o Reparo (TTR)

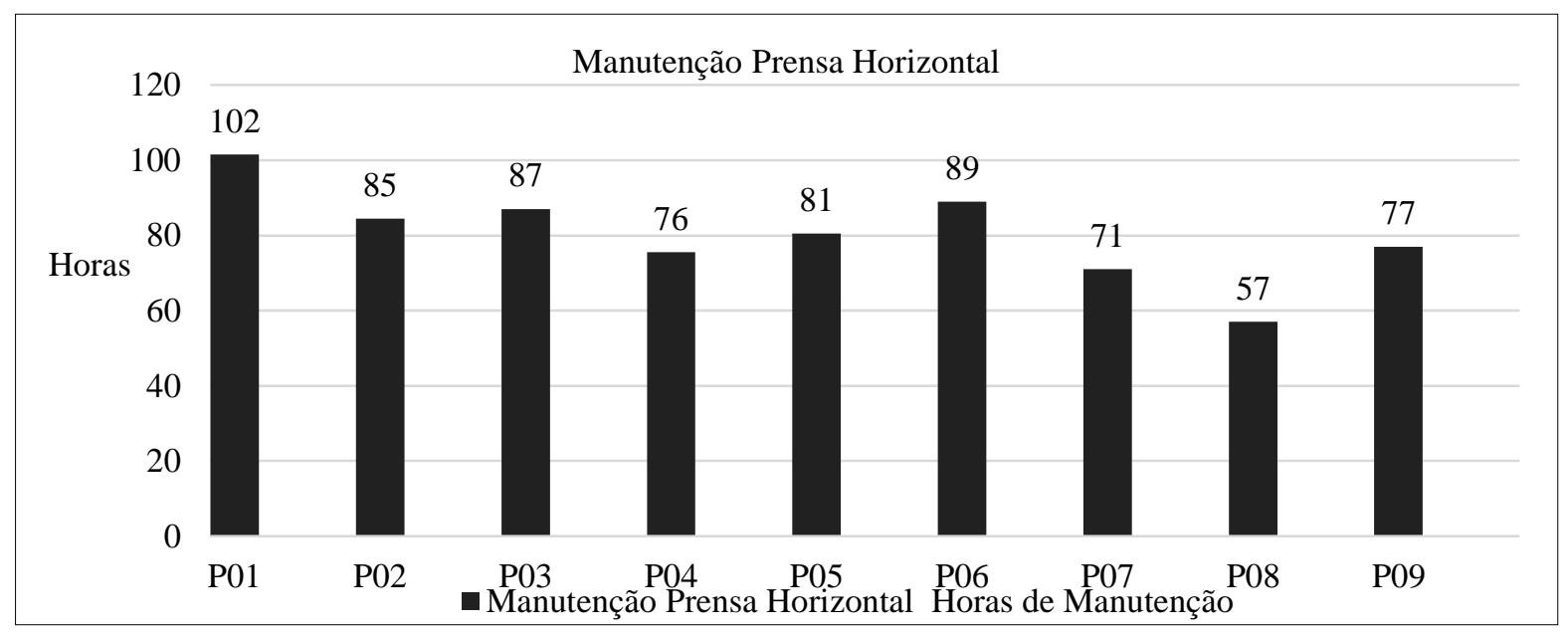

Fonte: Dados da pesquisa.

Com base no gráfico, identificou-se que a prensa P01 teve maior tempo de paradas somando os tempos das três falhas. Cabe ressaltar que as falhas são de mesma natureza e pelos mesmos componentes, então comparando com as demais, essa máquina necessita de uma maior atenção a fim de diagnosticar a causa de tais falhas.

Para ser possível realizar os cálculos de confiabilidade, com base na relação das datas entre falhas demonstradas na Tabela 1, foram calculados os dias entre essas falhas. Como demonstradas na Tabela 2 a seguir.

Tabela 2 - Histórico do Tempo Entre Falhas (TBF)

\begin{tabular}{|c|c|c|c|c|c|c|c|c|c|}
\hline \multicolumn{10}{|c|}{ Tempo Entre Falhas em Dias } \\
\hline \multirow[t]{2}{*}{ Falhas } & \multicolumn{9}{|c|}{ Prensas Excêntricas Horizontais } \\
\hline & P 01 & $\mathrm{P} 02$ & P 03 & P 04 & P 05 & P 06 & P 07 & P 08 & P 09 \\
\hline $1^{\circ}$ Falha & 65 & 75 & 80 & 73 & 70 & 65 & 85 & 68 & 90 \\
\hline $2^{\circ}$ Falha & 36 & 74 & 64 & 33 & 54 & 42 & 37 & 61 & 29 \\
\hline $3^{\circ}$ Falha & 26 & 59 & 33 & 27 & 66 & 26 & 63 & 66 & 20 \\
\hline $4^{\circ}$ Falha & 12 & 23 & 56 & 67 & 36 & 69 & 44 & 69 & 58 \\
\hline $5^{\circ}$ Falha & 26 & 25 & 20 & 26 & 28 & 22 & 27 & 34 & 27 \\
\hline $6^{\circ}$ Falha & 20 & 39 & 18 & 20 & 28 & 20 & 24 & 33 & 18 \\
\hline $7^{\circ}$ Falha & 15 & 18 & 21 & 25 & 32 & 27 & 33 & & 27 \\
\hline $8^{\circ}$ Falha & 21 & 20 & 16 & 11 & 29 & 11 & 28 & & 14 \\
\hline $9^{\circ}$ Falha & 17 & 18 & 21 & 18 & & 15 & & & 17 \\
\hline $10^{\circ}$ Falha & 16 & & 14 & 13 & & 18 & & & 15 \\
\hline $11^{\circ}$ Falha & 17 & & & 15 & & 14 & & & 13 \\
\hline $12^{\circ}$ Falha & 16 & & & 20 & & 16 & & & 24 \\
\hline $13^{\circ}$ Falha & 15 & & & & & & & & \\
\hline $14^{\circ}$ Falha & 21 & & & & & & & & \\
\hline $15^{\circ}$ Falha & 25 & & & & & & & & \\
\hline
\end{tabular}

Fonte: Dados da pesquisa. 
Confiabilidade de prensas excêntricas horizontais paralelas de uma linha de fabricação de embalagens metálicas para bebidas

A Engenharia de manutenção da Empresa $X$ atualmente adota a estratégia de manutenção corretiva como resultado da falta de indicativos das reais condições de operação das máquinas e equipamentos. Essa metodologia pode gerar muitos prejuízos, visto que é uma forma de manutenção imediatista e inesperada, resultando em parada do equipamento sem haver um planejamento prévio necessário para que, ao realizar as intervenções, todos os recursos estejam disponíveis. Para reverter essa situação foram calculados os indicadores de confiabilidade: MTTR, MTBF, disponibilidade e confiabilidade, e seus resultados estão descritos na Tabela 3.

Tabela 3 - Resultados dos Cálculos de Confiabilidade

\begin{tabular}{c|c|c|c|c|c}
\hline \multicolumn{5}{c}{ Cálculos de Confiabilidade } \\
\hline Prensas & MTTR & MTBF & Disponibilidade & $\lambda$ - Taxa de Falhas & R - Confiabilidade \\
\hline P01 & 3,303 & 234,09 & $98,61 \%$ & 0,004271845 & $68,08 \%$ \\
P02 & 3,143 & 275,89 & $98,87 \%$ & 0,003624595 & $72,17 \%$ \\
P03 & 3,103 & 266,38 & $98,85 \%$ & 0,003754045 & $71,33 \%$ \\
P04 & 3,125 & 321,88 & $99,04 \%$ & 0,003106796 & $75,61 \%$ \\
P05 & 3,074 & 286,11 & $98,94 \%$ & 0,003495146 & $73,01 \%$ \\
P06 & 3,207 & 266,38 & $98,81 \%$ & 0,003754045 & $71,33 \%$ \\
P07 & 3,000 & 321,88 & $99,08 \%$ & 0,003106796 & $75,61 \%$ \\
P08 & 3,105 & 406,58 & $99,24 \%$ & 0,002459547 & $80,14 \%$ \\
P09 & 3,160 & 309,00 & $98,99 \%$ & 0,003236246 & $74,73 \%$ \\
\hline
\end{tabular}

Fonte: Dados da pesquisa.

Com a organização e análise dos dados obtidos com a pesquisa no software de gerenciamento de manutenção da empresa e pela utilização do software Excel 2013®, calculou-se com a equação (3) o tempo médio para reparo (MTTR) para cada prensa, como mostra a Tabela 3. Matematicamente, é o tempo total de manutenções corretivas divididas pelo total de intervenções. Os resultados desse cálculo demonstraram que o tempo médio para cada reparo realizados nas nove prensas se manteve praticamente constante, havendo pequenas variações, significando que o efetivo de manutenção atua de maneira uniforme e constante na resolução da falha.

Vale ressaltar que é necessário deixar o MTTR cada vez mais baixo, pois ele significa máquina parada e utilização de recurso, como exemplo, mão de obra e peças sobressalentes. Não existe uma referência de valor para o MTTF, isso varia para cada tipo de maquinário e equipamento, mas deve-se mantê-lo sempre o mais baixo possível. Isso significa realizar de maneira mais rápida e assertiva as intervenções de manutenção e mesmo sendo manutenções corretivas, a equipe dever ser bem treinada para que a rapidez não resulte em erro. 
Confiabilidade de prensas excêntricas horizontais paralelas de uma linha de fabricação de embalagens metálicas para bebidas

Posteriormente, calculou-se o tempo médio entre falhas (MTBF) utilizando a equação (4), que é expressa pelo quociente entre o somatório das horas em que o equipamento não apresentou falhas pelo número de paradas para intervenções corretivas. Os resultados desse cálculo podem ser observados na Tabela 3. O MTBF é um indicador relevante, pois a empresa pode se basear nele para identificar como a manutenção está sendo administrada de um modo geral. Sendo que ao contrário do MTTR, quanto maior o resultado do MTBF, melhor.

O MTBF foi empregado para cada prensa individualmente para facilitar as ações a serem aplicadas, visto que tais ações serão executadas individualmente também. Os resultados adquiridos indicam que a máquina $\mathrm{P} 01$ possui o menor tempo entre as falhas, significando maior números de falhas, ao contrário da máquina P08 que possui quase o dobro do tempo da P01. Então é plausível identificar qual a causa dessa diferença, já que são os mesmos tipos de máquinas e, principalmente, identificar o porquê da prensa P08 apresentar menos falhas, a fim de replicar para as outras.

Com os resultados obtidos do MTTR e MTBF, calculou-se a disponibilidade inerente de cada máquina, esse indicativo é obtido pela equação (2) e seus resultados estão expressos na Tabela 3. A disponibilidade dos equipamentos é um indicativo importante para o planejamento da manutenção, pois ele mostra qual máquina ou equipamento merece maior prioridade. Analisando os resultados obtidos, constatou-se que a disponibilidade possui valores bem próximos de $100 \%$, porém esses valores podem ser melhorados e, para isso, é necessário formular uma estratégia de manutenção com a finalidade de elevar a disponibilidade, tendo em vista que basta apenas procurar sempre elevar o MTBF e reduzir o MTTR.

Por fim, utilizando a equação (6) foi calculado a confiabilidade individual dos equipamentos e seus resultados estão expressos na Tabela 3. Analisando os valores obtidos, notou-se que, apesar das máquinas apresentarem a disponibilidade elevada, a confiabilidade das máquinas estão baixas, apenas uma está acima de $80 \%$. A confiabilidade está ligada ao futuro e é uma projeção probabilística que aponta as chances de o equipamento funcionar perfeitamente em um determinado espaço de tempo, então quanto mais próximo de $100 \%$, melhor para que o processo se torne também confiável. Para facilitar o entendimento da relação entre disponibilidade e confiabilidade foi gerado o Gráfico 3 com base nos dados obtidos. 
Confiabilidade de prensas excêntricas horizontais paralelas de uma linha de fabricação de embalagens metálicas para bebidas

Gráfico 3 - Relação Entre Disponibilidade e Confiabilidade

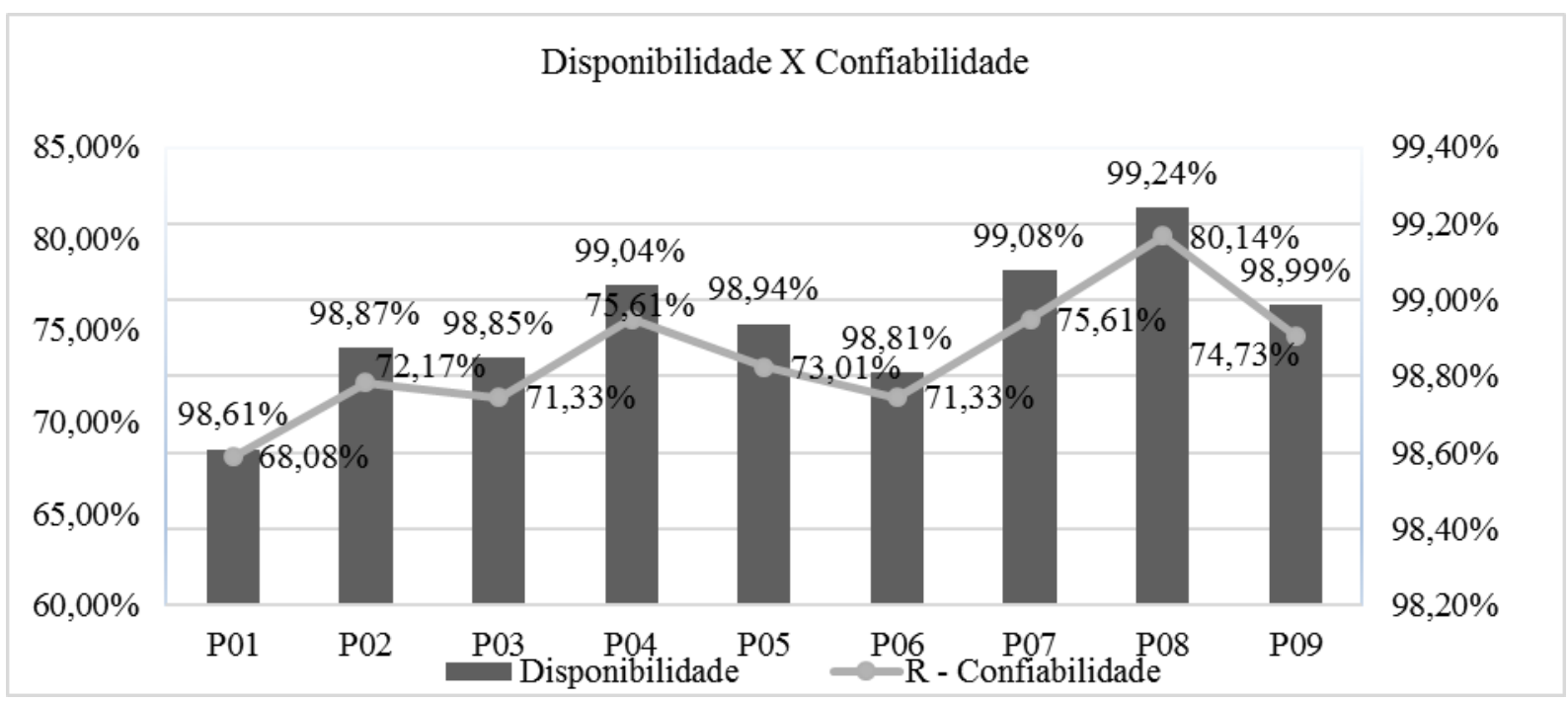

Fonte: Dados da pesquisa.

Observando-se o Gráfico 3, verifica-se que a máquina P08 deve ser melhor estudada para que os fatores que causam a sua disponibilidade e confiabilidade mais alta em relação as outras possam ser utilizados como exemplo. Ao fazer isso, os mesmos fatores poderão ser replicados para as máquinas que apresentaram pior desempenho em procedimento futuros, como a P01 por exemplo, para tentar manter maior equalização dos comportamentos das máquinas.

Outra estratégia é aumentar a confiabilidade do processo utilizado na Empresa X. O agrupamento das máquinas em um arranjo paralelo permite que confiabilidade de cada máquina seja multiplicada, deixando o processo mais confiável. Ao aplicar os valores das confiabilidades individuais na equação (7), obteve-se a confiabilidade do sistema em paralelo, como mostrado na Tabela 4.

Tabela 4 - Cálculo da Confiabilidade para sistemas em paralelo

\begin{tabular}{l} 
Confiabilidade para sistemas em paralelo \\
\hline Paralelo $=1-(1-\mathrm{R} 01) \times(1-\mathrm{R} 02) \times(1-\mathrm{R} 03) \ldots \times(1-\mathrm{R} 09)$ \\
Paralelo $=\quad 99,9994 \%$ \\
\hline Fonte: Dados da pesquisa.
\end{tabular}

O resultado confirmou o aumento da confiabilidade, deixando o sistema com 99,99\% de confiabilidade. Porém, ressalta-se que, apesar do sistema não parar por falha em uma máquina, a empresa está perdendo produtividade, pois haverá máquina parada. Então é GEPROS. Gestão da Produção, Operações e Sistemas, v. 15, nº 2, p. 253 - 287, 2020. 
Confiabilidade de prensas excêntricas horizontais paralelas de uma linha de fabricação de embalagens metálicas para bebidas

necessário traçar estratégias de manutenção preventiva ou, até mesmo, preditivas a fim de aumentar a confiabilidade individual das prensas excêntricas horizontais. Uma opção seria a manutenção deve evoluir juntamente com o equipamento, que para Souza (2008) a empresa pode chegar à excelência.

\section{CONCLUSÕES}

O objetivo deste trabalho foi usar os cálculos de confiabilidade para gerar indicativos das reais condições de operação de nove prensas excêntricas horizontais do setor de estamparia de uma linha de fabricação de latas de alumínio para bebidas. Foi realizado um relato técnico da aplicação de indicadores de manutenção num ambiente de manufatura. $\mathrm{O}$ estudo se limita por ser realizado em um único período da sua vida de operação, pois os equipamentos começaram a operar no final de 2017, período em que foi iniciada a coleta de dados, então seu nível de degradação ainda está baixo, o que significa que se posteriormente o estudo for repetido, poderá haver diferença nos resultados.

Para este estudo foram revisados conceitos sobre manutenção industrial e confiabilidade de equipamentos industriais. Na manutenção industrial, revisou-se conceitos e aplicabilidade dos tipos de manutenção: corretiva, preventiva, preditiva, manutenção produtiva total e, por fim, a manutenção centrada em confiabilidade, que utiliza como base os cálculos de confiabilidade para tomada de decisões. Sobre confiabilidade fora abordados conceitos sobre a disponibilidade de equipamentos industrial, tempo médio até o reparo e tempo médio entre falhas.

$\mathrm{Na}$ prática, a método indicado foi aplicado nas prensas excêntricas horizontais, por serem os equipamentos responsáveis pelo o início do processo e pelo fato de suas falhas prejudicarem todo o sistema produtivo. Foram obtidos do sistema de informação da empresa dados de tempos entre falhas e tempos até o reparo do equipamento. As informações foram analisadas com o auxílio do software Excel 2013®.

Tal trabalho se mostrou relevante para a empresa estudada, pois com os resultados foi possível analisar se a estratégia de manutenção utilizada pela empresa que, atualmente, usa a manutenção corretiva, possui eficiência principalmente pelo uso da configuração da linha de produção em paralelo. A pesquisa constatou que o equipamento está em uma fase de pouco desgaste e que não poderia apresentar o número de falhas tal qual o identificado em um 
Confiabilidade de prensas excêntricas horizontais paralelas de uma linha de fabricação de embalagens metálicas para bebidas

período curto como o estudado. Essa constatação evidenciou a necessidade de uma nova estratégia, no caso, será utilizada a manutenção preventiva para prevenir as falhas.

A contribuição prática do artigo está numa aplicação real com dados brutos de uma multinacional que poderá servir de exemplo para engenheiros de produção calcularem indicadores em seus equipamentos. Em relação a literatura sobre o tema, a pesquisa auxilia na discussão, já que Calache et al. (2019, p. 2) afirmam que "apesar da importância que a manutenção industrial apresenta, a literatura carece de pesquisas que explorem modelos". A contribuição teórica da pesquisa foi apresentar um modelo de confiabilidade de prensas para o setor em estudo, apresentando modelos matemáticos de cálculo da confiabilidade, e como usar na pratica em uma indústria, evidenciando os resultados obtidos com a busca.

Portanto, mensurar a confiabilidade e disponibilidade dos equipamentos, assim como os outros indicativos aqui mencionados, facilita a tomada de decisões e o planejamento da manutenção. Também indica qual a eficiência do efetivo de manutenção ao executar as intervenções corretivas, sendo que isso só é possível por se possuir indicativos das reais condições dos equipamentos, mensurados pelos cálculos de confiabilidade.

Por fim, como continuidade do estudo, sugere-se a aplicação do método em toda a linha produtiva da empresa estudada, a fim de mensurar e diagnosticar as reais condições de operação e maneabilidade da linha produtiva como um todo.

\section{Referências}

ABRALATAS. Processo de fabricação da lata de alumínio para bebidas. 2018. Disponível em: http://www.abralatas.org.br/. Acesso em: 07 abr. 2018.

ASSOCIAÇÃO BRASILEIRA DE NORMAS TECNICAS. ABNT NBR 5462: confiabilidade e mantenabilidade. Rio de Janeiro: ABNT, 1994.

AZEVEDO, P. C. Estudo da geração de ruído em prensa mecânica excêntrica de 900 toneladas. 2003. 117 f. Dissertação (Mestrado em Engenharia Mecânica) - Universidade Federal de Santa Catarina, Florianópolis, 2003.

BARAN, L. R. Manutenção centrada em confiabilidade aplicada na redução de falhas: um estudo de caso. 2011. 103 f. Monografia (Especialização em Gestão Industrial: Produção e Manutenção) - Universidade Tecnológica Federal do Paraná, Ponta Grossa, 2011.

BRANCO FILHO, G. Dicionário de termos de manutenção e confiabilidade. Rio de Janeiro: Ciência Moderna, 2000.

GEPROS. Gestão da Produção, Operações e Sistemas, v. 15, nº 2, p. 253 - 287, 2020 
Confiabilidade de prensas excêntricas horizontais paralelas de uma linha de fabricação de embalagens metálicas para bebidas

CAIADO, R. G. G.; LIMA, G. B. A.; QUELHAS, O. L. G. Aspectos da aplicação da manutenção centrada em confiabilidade. In: CONGRESSO NACIONAL DE EXCELỂNCIA EM GESTÃO, 11., 2015, Rio de Janeiro. Anais [...]. Rio de Janeiro: Congresso Nacional de Excelência em Gestão, 2015. p.1-17.

CALACHE, L. D. D. R.; et al. Proposta de um modelo de avaliação e de seleção de fornecedores de manutenção industrial utilizando Fuzzy-TOPSIS. Gestão da Produção, v. 26, n. 2, p. 1-11, 2019.

CALARGE, F. A.; et al. Análise e avaliação da qualidade de serviços internos com foco na manutenção de utilidades em uma empresa de manufatura. Production, v. 26, n. 4, p. 724741, dez. 2016.

CERVEIRA, D. S.; SELLITTO, M. A. Manutenção centrada em confiabilidade (MCC): análise quantitativa de um forno elétrico a indução. Revista Produção Online, v. 15, n. 2, p.405-432, 2015.

CORREA, R. F.; DIAS, A. Modelagem matemática para otimização de periodicidade nos planos de manutenção preventiva. Gestão da Produção, v. 23, n. 2, p. 267-278, 2016.

COSTA, M. de A. Gestão estratégica da manutenção: uma oportunidade para melhorar o resultado operacional. 2013. 103 f. Trabalho de Conclusão de Curso (Graduação em Engenharia de Produção) - Universidade Federal de Juiz de Fora, Juiz de Fora, 2013.

FOGLIATTO, F. S.; RIBEIRO, J. L. D. Manutenção centrada em confiabilidade. In: FOGLIATTO, F. S.; RIBEIRO, J. L. D. Confiabilidade e manutenção industrial. Rio de Janeiro: Elsevier, 2011. cap. 12, p. 217-232.

GUEVARA, W.; CARDENAS, A. V.; CAMPEROS, J. A. G. Metodología para evaluar el factor confiabilidad en la gestión de proyectos de diseño de equipos industriales. Tecnura, $v$. 19, n. spe, p. 129-141, 2015.

KOMNINAKIS, D.; PIRATELLI, C. L.; ACHCAR, J. A. Análise de confiabilidade para formulação de estratégia de manutenção de equipamentos em uma empresa da indústria alimentícia. Revista Produção Online, v. 18, n. 2, p. 560-592, 2018.

LUCATELLI, M. V. Proposta de aplicação da manutenção centrada em confiabilidade em equipamentos médico-hospitalares. 2002. 285 f. Tese (Doutorado em Engenharia Elétrica) - Universidade Federal de Santa Catarina, Florianópolis, 2002.

MARÇAL, R. F. M. Um método para detectar falhas incipientes em máquinas rotativas baseado em análise de vibrações e lógica fuzzy. 2000. 124 f. Tese (Doutorado em Engenharia Metalúrgica, de Minas e dos Materiais) - Universidade Federal do Rio Grande do Sul, Porto Alegre, 2000. 
Confiabilidade de prensas excêntricas horizontais paralelas de uma linha de fabricação de embalagens metálicas para bebidas

MARQUES, A. P.; et al. Técnicas preditivas de manutenção em transformadores de potência um estudo de caso. In: WORLD CONGRESS ON SYSTEMS ENGINEERING AND INFORMATION TECHNOLOGY, 1., 2013, Porto. Anais [...]. Porto: COPEC, 2013. p. 4347.

MARIN, J. G.; et al. La gerencia del mantenimiento: una evisión. Dimens. empres., Barranquilla, v. 14, n. 2, p. 127-142, 2016.

MANSANO, D. R. Aumento da produtividade em uma prensa mecânica excêntrica de estampagem de rebites tubulares de metais não-ferrosos. 2008. 40 f. Trabalho de Conclusão de Curso (Graduação em Engenharia Mecânica Automação e Sistemas) Universidade São Francisco, Campinas, 2008.

MOUBRAY, J. Introdução à manutenção centrada na confiabilidade. São Paulo: Aladon, 2001.

NOGUEIRA, C. F.; GUIMARÃES, L. M.; SILVA, M. D. B. Manutenção industrial: implementação da manutenção produtiva total (TPM). E-xacta, v. 5, n. 1, p.175-194, 2012.

NUNES, E. L. Manutenção centrada em confiabilidade (MCC): análise da implantação em uma sistemática de manutenção preventiva consolidada. 2001. 146 f. Dissertação (Mestrado em Engenharia de Produção) - Programa de Pós-graduação de Engenharia de Produção, Universidade Federal de Santa Catarina, Florianópolis, 2001.

OLIVEIRA, L. G.; PAIVA, E. J.; PAIVA, A. P. Aplicação do método de Monte Carlo para a previsão de falhas: uma ferramenta de apoio à gestão da manutenção. Revista Produção Online, v. 19, n. 1, p. 72-101, 2019.

OLIVEIRA, J. C. S.; SILVA, A. P. Análise de indicadores de qualidade e produtividade da manutenção nas indústrias brasileiras. GEPROS. GEPROS: Gestão da Produção, Operações e Sistemas, v.11, n. 3, p. 53-69, 2013.

OTANI, M.; MACHADO, W. A proposta de desenvolvimento de gestão da manutenção industrial na busca da excelência ou classe mundial. Revista Gestão Industrial, v. 5, n. 2, p. 1-16, 2008.

SALVI, A. L. et al. Modelo de prensa excêntrica: automatização e adequação de segurança. In: Semana da Ciência e Tecnologia, 3., 2014, Luzerna. Anais [...]. Luzerna: SECITEC, 2014. p. 1-18.

SELLITTO, M. A. Análise estratégica da manutenção de uma linha de fabricação metalmecânica baseada em cálculos de confiabilidade de equipamentos. GEPROS: Gestão da Produção, Operações e Sistemas, v. 3, n. 2, p. 97-108, 2007.

SOUZA, J. B. Alinhamento das estratégias do planejamento e controle da manutenção (pcm) com as finalidades e função do planejamento e controle da produção (PCP): uma 
Confiabilidade de prensas excêntricas horizontais paralelas de uma linha de fabricação de embalagens metálicas para bebidas

abordagem analítica. 2008a. 169 f. Dissertação (Mestrado em Engenharia de Produção) Universidade Tecnológica Federal do Paraná, Campus Ponta Grossa, Ponta Grossa, 2008.

SOUZA, R. Q. Metodologia e desenvolvimento de um sistema de manutenção preditiva visando a melhoria da confiabilidade de ativos de usinas hidrelétricas. 2008b. $226 \mathrm{f}$. Dissertação (Mestrado em Sistemas Mecatrônicos) - Departamento de Engenharia Mecânica, Faculdade de Tecnologia da Universidade de Brasília, Brasília, 2008.

SOUZA, S. S.; LIMA, C. R. C. Manutenção centrada em confiabilidade como ferramenta estratégica. In: ENCONTRO NACIONAL DE ENGENHARIA DE PRODUÇÃO, 23., 2003, Ouro Preto. Anais [...]. Ouro Preto: ENEGEP, 2003. p. 1-8.

STOLLE MACHINERY. Manual de operação e manutenção formadora standun B6/B7. Brunswick: Centennial, 2016.

TELES, J. Confiabilidade de equipamentos industriais. Confiabilidade: O que é e Como Medir? 2017. Disponível em: https://engeteles.com.br/o-que-e-confiabilidade/. Acesso em: 10 out. 2018.

XENOS, H. G. Gerenciando a manutenção produtiva. Belo Horizonte: Desenvolvimento Gerencial, 1998. 